\title{
Developing a Method to Simulate and Evaluate Effects of Adaptation Strategies to Climate Change on Wheat Crop Production: A Challenging Multi-Criteria Analysis ${ }^{\dagger}$
}

\author{
Christophe Gigot ${ }^{1, *(D)}$, Doriane Hamernig ${ }^{1, *}$, Violaine Deytieux ${ }^{2, *}$, Ibrahima Diallo ${ }^{2}$, Olivier Deudon ${ }^{1}$, \\ Emmanuelle Gourdain ${ }^{1}$, Jean-Noël Aubertot ${ }^{3}$, Marie-Hélène Robin ${ }^{3}$, Marie-Odile Bancal ${ }^{4} \mathbb{D}$, Laurent Huber 4 \\ and Marie Launay ${ }^{5}$
}

1 ARVALIS-Institut du Végétal, Station Expérimentale, 91720 Boigneville, France; o.deudon@arvalis.fr (O.D.); e.gourdain@arvalis.fr (E.G.)

2 INRAE, UE115 Domaine Expérimental d’Epoisses, 21000 Dijon, France; ibrahima-koula.diallo@inrae.fr

3 INRAE-INPT-ENSAT-EI-Purpan, Université de Toulouse, UMR 1248 AGIR, 31326 Castanet-Tolosan, France; jean-noel.aubertot@inrae.fr (J.-N.A.); mh.robin@purpan.fr (M.-H.R.)

4 INRAE, UMR1402 ÉcoSys, AgroParisTech, Université Paris-Saclay, 78850 Thiverval-Grignon, France; marie-odile.bancal@inrae.fr (M.-O.B.); laurent.huber@inrae.fr (L.H.)

$5 \quad$ INRAE, US1116 AgroClim, 84914 Avignon, France; marie.launay@inrae.fr

* Correspondence: c.gigot@arvalis.fr (C.G.); d.hamernig@arvalis.fr (D.H.); violaine.deytieux@inrae.fr (V.D.)

+ Presented at the 13th EFITA International Conference, online, 25-26 May 2021.

check for updates

Citation: Gigot, C.; Hamernig, D.; Deytieux, V.; Diallo, I.; Deudon, O.; Gourdain, E.; Aubertot, J.-N.; Robin, M.-H.; Bancal, M.-O.; Huber, L.; et al. Developing a Method to Simulate and Evaluate Effects of Adaptation Strategies to Climate Change on Wheat Crop Production: A Challenging Multi-Criteria Analysis. Eng. Proc. 2021, 9, 21. https:// doi.org/10.3390/engproc2021009021

Academic Editors: Dimitrios Kateris and Maria Lampridi

Published: 25 November 2021

Publisher's Note: MDPI stays neutral with regard to jurisdictional claims in published maps and institutional affiliations.

Copyright: (c) 2021 by the authors. Licensee MDPI, Basel, Switzerland. This article is an open access article distributed under the terms and conditions of the Creative Commons Attribution (CC BY) license (https:/ / creativecommons.org/licenses/by/ $4.0 /)$.

\begin{abstract}
Adaptation of cropping management strategies is necessary to ensure the sustainability of our agriculture, which is facing threats arising from climate change. A methodology is proposed to find out and compare the most promising adaptation strategies in this context considering both biotic and abiotic stresses. A set of pre-selected strategies were evaluated based on economic, plant health and environmental criteria. A dedicated workflow combining the STICS crop model, epidemiological models and multi-criteria analysis was designed, implemented and tested for a wheat production situation. Flexible by design, this methodology can consider different criteria weights to be used as an exchange support with stakeholders.
\end{abstract}

Keywords: climate change; wheat production; multi-criteria analysis; crop model; epidemiological model; adaptation strategy

\section{Introduction}

To combat climate change (CC), stakeholders have requested the development of cropping and breeding strategies that limit the impacts of increasing abiotic stress on plant production. This often overlooks plant health risk that is either directly induced by CC or indirectly through adaptations of agricultural practices. In this context, the OPERATE project ("crop disease response to climate change adaptation") aims to address this issue for arable crops by evaluating the impact of possible adaptation strategies to CC on three sets of criteria (economics, plant health and environment). A methodology was developed, implemented and tested on a wheat crop situation in a climatic context located in the French region of Haut de France.

\section{Approach}

The first step was to precisely define a set of potential adaptation strategies to abiotic stress that may be experienced by wheat crop in the next decades. Two groups of agronomical levers were proposed based on preliminary surveys conducted with stakeholders [1]: (i) compensation for limited water resources using different irrigation approaches or mulches to maintain soil moisture; and (ii) avoidance of unfavorable conditions shifting sowing dates and/or mobilizing earliness of wheat varieties. Other agronomical levers were 
considered due to their potential impact on disease development (biotic stress): (i) tillage or no tillage; (ii) disease resistance of wheat varieties; and (iii) nature of the previous crop. The prospective impacts of the adaptation strategies on the economic, plant health and environmental criteria were simulated, mobilizing climate change, crop and disease models. The required steps to identify and characterize the most promising strategies were implemented within the operational workflow described in Figure 1.
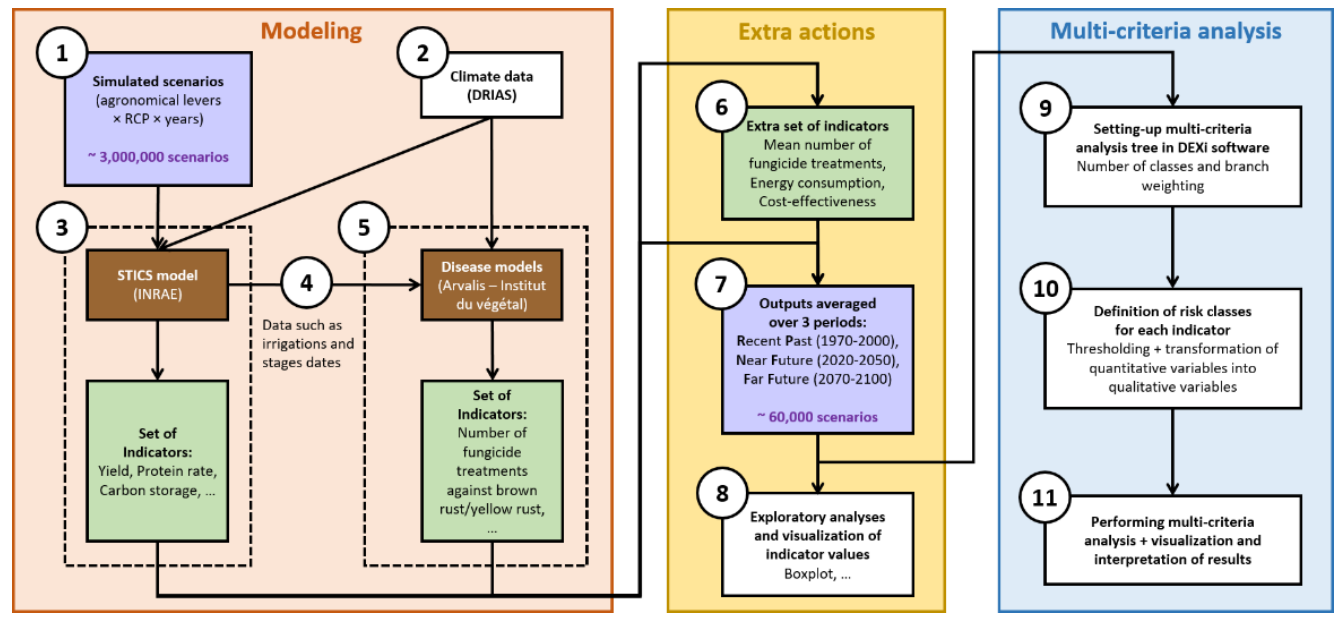

Figure 1. Workflow implemented to simulate impacts of candidate adaptation strategies to climate change and identify the most promising ones for wheat crop situation.

In this workflow, all possible combinations of agronomical levers, prospective CC scenarios and each year between 1970 and 2100 were used as inputs of the crop and disease models, which resulted in a total of about 3,000,000 scenarios (step 1 in Figure 1). Two CC scenarios were considered: either the moderate Representative Concentration Pathway (RCP [2]) 4.5 or the alarmist RCP 8.5, using prospective weather data (Météo-France, CERFACS, IPSL-2014) from the DRIAS platform [3] (step 2). The models were combined in a seamless way to simulate the various effects of adaptation strategies. Simulations with STICS crop model [4] were conducted to estimate production (e.g., yield, nitrogen grain contents) and environmental (e.g., nitrate loss, $\mathrm{N}_{2} \mathrm{O}$ emissions) indicators (step 3). In addition to inputs in common with STICS, disease models developed by Arvalis-Institut du végétal [5-9] used output data from STICS (irrigation and phenology, step 4) (i) to assess risks relative to Septoria tritici blotch, yellow and brown rusts, eyespot and Fusarium head blight (step 5) and (ii) to compute an indicator of fungicide use needed to maintain damage-free crops (step 6).

Supplementary indicators (energy consumption and semi-net margin) were estimated through the CRITER tool [10] (step 6). To focus on tendencies, all the indicators' values were averaged on subsets of years corresponding to three distinct climatic periods: reference past (1970-2000); near future (2020-2050); and far future (2070-2100) (step 7)-for one location (Estrées-Mons, France). Exploratory analyses were performed at this stage to (i) visualize and check the outputs; and (ii) identify expected and possible unexpected effects of levers (step 8). This allows us to highlight necessary compromises to reach a "good" adaptation relevancy to CC (e.g., antagonist effect of sowing date on potential yield and sparing use of fungicides). To identify promising strategies, multi-criteria analysis was performed using the software DEXi [11]. A qualitative decisional tree was designed to aggregate all the relevant indicators of the previously mentioned models into only one general criterion (adaptation relevancy to CC) with five levels, ranging from "very poorly adapted" to "very well adapted". A set of criteria weights was chosen for the aggregation, but such parameters could be modified depending on the aims of the stakeholders (step 9). To be able to use DEXi with the indicators, thresholding was performed on the quantitative indicators to obtain qualitative criteria with balanced classes that the qualitative decisional 
tree can handle (step 10). Outputs of multi-criteria analysis were plotted to facilitate their interpretation. In addition, clustering methods on the principal components from multiple correspondence analysis (MCA) were applied on the best scenarios (with high adaptation relevancy to $\mathrm{CC}$ ) to characterize the diversity of promising strategies (step 11).

\section{Example of Application}

Some outputs of a multi-criteria analysis performed on bread wheat crop situation using a specific decision tree (not detailed) are shown hereinafter as a proof of concept of the method, without any actual field-scale application at this time.

\subsection{Ranking of Adaptation Scenario Relevancy}

This multi-criteria analysis allowed for ranking the scenarios according to their adaptation relevancy to CC. The Figure 2 shows how two kinds of irrigation strategies, automatic irrigation when water comfort status (water comfort status corresponds to actual evapotranspiration divided by maximum evapotranspiration) is below 0.7 (IRA) and four fixed irrigation dates (IRF), may impact the final aggregated criterion "adaptation relevancy to $\mathrm{CC}^{\prime \prime}$ in reference past (RP) and far future (FF) for RCP 8.5. In this example, the IRA strategy seems to be promising because it makes it possible to drastically reduce the number of very poorly (- -) and poorly (-) adapted scenarios in the future, contrary to the IRF strategy.

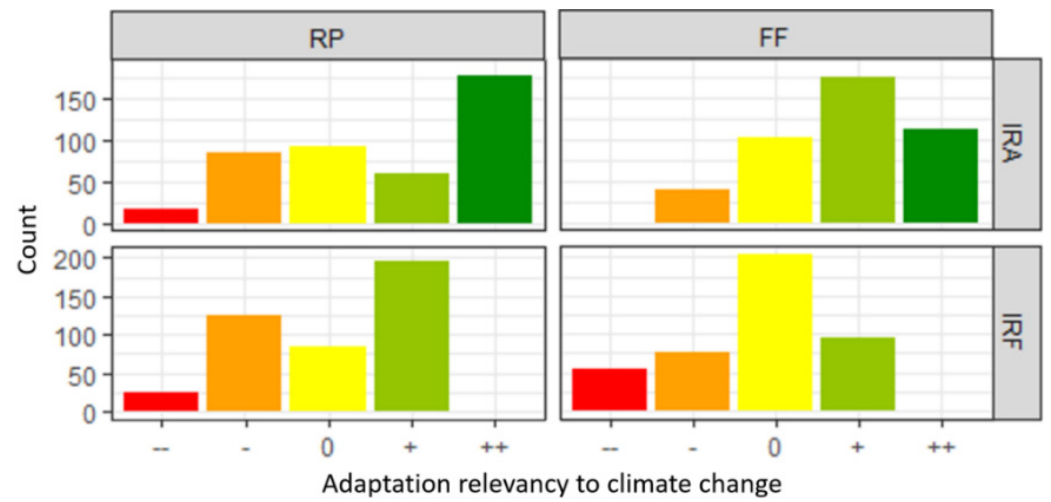

Figure 2. Impact on the adaptation relevancy to climate change (CC) of the irrigation strategies IRA (automatic irrigation when under significant water stress) and IRF (four fixed irrigation dates) for reference past (RP) and far future (FF) under the most alarmist CC scenario (Representative Concentration Pathway 8.5). Five categories of adaptation relevancy are defined: very poorly adapted (- $)$, poorly adapted (-), moderately adapted (0), well adapted (+), very well adapted (++). The $y$-axis corresponds to the number of tested scenarios that fall into each of these categories.

\subsection{Clustering to Identify Similar Scenarios in Terms of Adaptation Relevancy}

To characterize the diversity of promising strategies, clustering methods on principal components from MCA can be applied on the scenarios with the best levels of adaptation relevancy to CC (well adapted and very well adapted, i.e., + and ++ in Figure 2). Using five clusters of similar promising strategies suggested by this proof-of-concept multicriteria analysis (data not shown), it was possible to identify a cluster characterized by (i) relatively high economic and plant health scores, but medium environmental scores and (ii) a prevalence of corn as previous crop while other levers are not very discriminant. Another cluster was characterized by (i) high economic and environmental scores, but poor plant health scores and (ii) no tillage, high prevalence of canola as previous crop, and low global disease resistance which, as expected, are combined with a dominant profile of late sowing dates to escape diseases. 


\section{Conclusions and Perspectives}

This flexible method potentially allows us to deal with a large range of locations, soil types, crop production, adaptation strategies, and decision trees with contrasted criteria weights. Using an indicator considering interactions between plant diseases to be more consistent with field situations would be interesting. The outputs can serve as support in discussions with stakeholders about most promising strategies to be considered to limit the impacts of CC on crop production, or conversely, the most damaging strategies to avoid in the context of CC. Getting feedback from stakeholders is required to improve the relevance and legitimacy of this method.

Author Contributions: Conceptualization and validation, J.-N.A., M.-O.B., O.D., V.D., C.G., E.G., D.H., L.H., M.L. and M.-H.R.; methodology, M.-O.B., V.D., C.G., E.G., D.H. and M.L.; software O.D., V.D., C.G. and D.H.; investigation, I.D., V.D., C.G. and D.H.; data curation, M.-O.B., O.D., V.D., C.G., D.H. and M.L.; writing—original draft preparation, C.G. and D.H.; writing-review and editing, M.-O.B., O.D., V.D., C.G., E.G., D.H., M.L. and M.-H.R.; supervision, E.G. and V.D.; funding acquisition and project administration, M.-O.B., L.H. and M.L. All authors have read and agreed to the published version of the manuscript.

Funding: This research is part of the OPERATE project ("crop disease response to climate change adaptation") which received financial support from the ACCAF metaprogram of INRAE.

Data Availability Statement: All relevant data have been included in this manuscript.

Acknowledgments: The authors are grateful to Dominique Ripoche for its expertise and support in crop modeling with STICS. They also thank the anonymous reviewers for their comments.

Conflicts of Interest: The authors declare no conflict of interest.

\section{References}

1. Calluaud, M.; de Goulaine, B.; Ferrand, A. Construction d'une Méthode d'évaluation Multicritère de Stratégies d'adaptation Au Changement Climatique pour Les Filières Blé, Pomme de Terre et Tournesol; AgroSup: Dijon, France, 2019.

2. Moss, R.H.; Edmonds, J.A.; Hibbard, K.A.; Manning, M.R.; Rose, S.K.; Van Vuuren, D.P.; Meehl, G.A. The next Generation of Scenarios for Climate Change Research and Assessment. Nature 2010, 463, 747. [CrossRef] [PubMed]

3. Lémond, J.; Dandin, P.; Planton, S.; Vautard, R.; Pagé, C.; Déqué, M.; Franchistéguy, L.; Geindre, S.; Kerdoncuff, M.; Li, L.; et al. DRIAS: A Step toward Climate Services in France. Adv. Sci. Res. 2011, 6, 179-186. [CrossRef]

4. Brisson, N.; Mary, B.; Ripoche, D.; Jeuffroy, M.H.; Ruget, F.; Nicoullaud, B.; Gate, P.; Devienne-Barret, F.; Antonioletti, R.; Durr, C.; et al. STICS: A Generic Model for the Simulation of Crops and Their Water and Nitrogen Balances. I. Theory and Parameterization Applied to Wheat and Corn. Agronomie 1998, 18, 311-346. [CrossRef]

5. Pierre, A.; Gourdain, E.; Couleaud, G.; Le Brix, X.; Moreau, F.; Deudon, O.; Heritier, E.; Simonneau, D.; Piraux, F. Elaboration d'un Modèle d'alerte de La Présence d'une Maladie Fongique: Application Au Pathosystème Puccinia Striiformis sur Blé Tendre d'hiver. In Proceedings of the AFPP-11ème Conférence Internationale sur les Maladies des Plantes, Tours, France, 7-9 September 2015.

6. Gouache, D.; Léon, M.S.; Duyme, F.; Braun, P. A Novel Solution to the Variable Selection Problem in Window Pane Approaches of Plant Pathogen-Climate Models: Development, Evaluation and Application of a Climatological Model for Brown Rust of Wheat. Agric. For. Meteorol. 2015, 205, 51-59. [CrossRef]

7. Gouache, D.; Bensadoun, A.; Brun, F.; Pagé, C.; Makowski, D.; Wallach, D. Modelling Climate Change Impact on Septoria Tritici Blotch (STB) in France: Accounting for Climate Model and Disease Model Uncertainty. Agric. For. Meteorol. 2013, 170, $242-252$. [CrossRef]

8. Georgel, F.; Huguet, B.; Couleaud, G.; Bouttet, D.; Gauchet, D.; Moreau, F.; Piraux, F.; Gourdain, E. Evaluer Le Risque Piétin Verse En Ile-de-France. In Proceedings of the AFPP-6ème Conférence sur les Moyens Alternatifs de Protection pour une Production Intégrée, Lille, France, 21 March 2017.

9. Gourdain, E.; Grignon, G. Piloter L'intervention Fusariose des Épis sur Blé. In Proceedings of the Végéphyl-12ème Conférence Internationale sur les Maladies des Plantes, Tours, France, 11-12 December 2018.

10. Hirschy, M.; Ravier, C.; Lorin, M. CRITER 5.4, un Outil de Caractérisation des Performances de Systèmes de Culture, Manuel D'utilisateur; INRAE: Paris, France, 2015.

11. Bohanec, M. DEXi: Program for Multi-Attribute Decision Making, User's Manual, Version 5.04; IJS Report DP-13100; Jožef Stefan Institute: Ljubljana, Slovenia, 2020. 